\title{
Avaliação de Políticas Comerciais em Modelos de Equilíbrio Geral com Pressuposições Alternativas Quanto aos Retornos de Escala
}

\author{
- ANgelo Costa Gurgel*
}

- ANTÔNIO Carvalho Campos**

\begin{abstract}
RESUMO
O presente trabalho apresenta um modelo aplicado de equilíbrio geral para quantificar os impactos de políticas comerciais para o Brasil e seus principais parceiros comerciais, sob pressuposições alternativas de retornos constantes e competição perfeita e de economias de escala e competição imperfeita. Os resultados revelam que os efeitos sobre o bem-estar são de maior intensidade quando economias de escala e competição imperfeita estão presentes no modelo. O maior aproveitamento de economias de escala, por meio dos efeitos racionalização e pró-competitivo nos segmentos industriais brasileiros, contribuem para este resultado. Ademais, reduções em preços aos consumidores e aumentos nas remunerações dos fatores primários de produção são de maior intensidade quando economias de escala e competição imperfeita são consideradas.
\end{abstract}

\section{PALAVRAS-CHAVE}

equilíbrio geral, economias de escala, competição imperfeita, política comercial

\section{ABSTRACT}

This paper presents an applied general equilibrium model used to quantify the impacts of trade policies on Brazil and its trade partners, under alternative assumptions of constant returns and perfect competition and economies of scale and imperfect competition. The results suggest that the welfare impacts are larger when economies of scale and imperfect competition are modeled. The exploitation of economies of scale contributes to this result, through rationalization and pro-competitive effects on the Brazilian industries. Also, decreasing in consumer prices and increasing in returns of primary factors are larger under assumptions of economies of scale and imperfect competition.

\section{KEY WORDS}

general equilibrium, economies of scale, imperfect competition, trade policy

\author{
JEL ClassificATION \\ C68, D43, FI2
}

\footnotetext{
* Professor da Faculdade de Economia, Administração e Contabilidade de Ribeirão Preto - USP. E-mail: angelocg@usp.br. * * Professor do Departamento de Economia Rural da Universidade Federal de Viçosa. E-mail: accampos@ufv.br. Endereço para contato: FEA-RP/USP, Av. dos Bandeirantes, 3900, Monte Alegre, 14090-900, Ribeirão Preto - SP. (Recebido em janeiro de 2005. Aceito para publicação em setembro de 2005).
} 


\section{INTRODUÇÃO}

A teoria de equilíbrio geral, também conhecida como teoria walrasiana dos mercados, tem sido utilizada para a formulação de modelos aplicados utilizados no estudo de diversos campos da ciência econômica, como relações de comércio, tributação, mudança tecnológica, crescimento econômico, entre outros. Modelos de equilíbrio geral são capazes de trazer um realismo maior em comparação com os de equilíbrio parcial, no que diz respeito à avaliação de políticas e choques que afetam um grande número de mercados simultaneamente, que apresentam ligações entre si. Contudo, a teoria de equilíbrio geral walrasiana considera um sistema de mercados perfeitamente competitivos e, portanto, desconsidera questóes relacionadas com economias de escala e competição imperfeita nos mercados.

De forma simplificada, economias de escala e retornos crescentes de escala são advindos da redução dos custos de produzir uma unidade de produto qualquer quando ocorre a expansão da produção. Em outras palavras, de acordo com Pratten (1971), as economias de escala seriam reduções em custos atribuídos a diferentes situaçôes de aumento da escala produtiva. Diversos autores procuraram destacar a importância de economias de escala e competição imperfeita na economia. Arrow et al. (1998) afirmam que retornos crescentes e competição imperfeita são fenômenos presentes e de suma importância na economia real, apesar de serem, em geral, ignorados nas universidades, com exceção para alguns cursos isolados como organização industrial. Segundo esses autores, economias de escala e competição imperfeita existem em muitas indústrias, sendo regra, em vez de exceção.

Considerando a presença de economias de escala nas firmas do setor industrial, a competitividade dos produtos nacionais no mercado mundial está relacionada com a capacidade de aproveitamento destas economias internas. A partir dessa constatação, é importante considerar que os efeitos de políticas comerciais em mercados com economias de escala podem ser consideravelmente diferentes daqueles observados em mercados com retornos constantes de escala e competição perfeita. Entretanto, nas análises sobre o processo de integração de mercados poucos estudos têm levado em consideração as imperfeiçóes dos mercados e, conseqüentemente, as recomendações de políticas advindas destes trabalhos consideram que os setores apresentam retornos constantes e comportamento competitivo.

A consideração de economias de escala e competição imperfeita em estudos que mensuram os impactos de acordos comerciais sobre a economia brasileira foi inaugurada por Flôres (1997), seguido de Cavalcante e Mercenier (1999), ambos mensurando impactos do MERCOSUL. Entre os estudos mais recentes sobre impactos de políticas comerciais, entretanto, poucos têm levado em consideração as imperfeições dos mer- 
cados e, conseqüentemente, as recomendações de políticas advindas destes trabalhos consideram que os setores apresentam retornos constantes e comportamento competitivo. Este é o caso dos estudos de Carvalho e Parente (1999), Barros et al. (2000), Valls Pereira (2001), Tourinho e Kume (2002), Gurgel et al. (2002) e Harrison et al. (2003).

Diante da grande procura por respostas a respeito de questões de políticas comerciais e das discussões recentes de aprofundamento da liberalização comercial torna-se importante avaliar o efeito de tais políticas considerando pressuposições de imperfeições a respeito da estrutura dos mercados. A modelagem de relações em mercados imperfeitos ainda permite apontar se existem diferenças consideráveis, em termos quantitativos e qualitativos, nos resultados de mudanças na política comercial que justifiquem o aprimoramento do método científico e o esforço de modelar mercados imperfeitos para o estudo de impactos de medidas de política.

Dessa forma, o objetivo do presente estudo é utilizar um modelo aplicado de equilíbrio geral, incorporando economias de escala e competição imperfeita, para quantificar os impactos de acordos comerciais sobre a economia brasileira e seus parceiros comerciais, comparando estes impactos com os obtidos pelos modelos tradicionais de retornos constantes e competição perfeita. A partir dos resultados obtidos, pretende-se contribuir para as discussões atuais a respeito das alternativas de políticas comerciais para o País. ${ }^{1}$

O trabalho está organizado em quatro seções, incluindo esta introdução. A seção a seguir apresenta a descrição do modelo utilizado e as modificações necessárias para acrescentar economias de escala e competição imperfeita. A segunda seção é dedicada à aplicação do modelo por meio da simulação de vários cenários alternativos de redução de barreiras comerciais e a última seção apresenta uma conclusão sobre os principais resultados obtidos.

1 Os trabalhos de Flôres (1997) e Cavalcante e Mercenier (1999) se preocuparam com mensurações de impactos do Mercosul sobre a economia brasileira introduzindo competição imperfeita na forma de competição monopolística (diferenciação do produto por firma), diferente do presente trabalho, que considera a estrutura de oligopólio nos mercados. Além disto, aqueles autores não comparam os resultados do modelo com competição imperfeira com aqueles que seriam obtidos sob competição perfeita e retornos constantes, considerando que as pressuposições de mercados imperfeitos e economias de escala tornam seus modelos mais realistas, o que não é consenso entre estudiosos que trabalham com modelos de equilíbrio geral. Gurgel e Campos (2003), por sua vez, utilizam a mesma modelagem de economias de escala e competição imperfeita do presente estudo. Analisam apenas os resultados da ALCA sobre as principais cadeias do agronegócio e não apresentam desagregação dos setores industriais. 


\section{OMODELO DE EQUILÍBRIO GERAL}

Os Modelos Aplicados de Equilíbrio Geral (MAEG) retratam o funcionamento de uma economia por meio das relaçóes matemáticas de comportamento dos agentes econômicos nos diversos mercados de bens, serviços e fatores de produção. Desta forma, são bastante úteis por captarem as relações entre os agentes econômicos e examinarem os efeitos diretos e indiretos advindos de alterações nas políticas públicas, como choques tarifários, modificações nas alíquotas de impostos e/ou subsídios e mesmo alterações de natureza tecnológica. (Sadoulet e De Janvry, 1995).

Os modelos aplicados de equilíbrio geral foram formulados segundo a teoria walrasiana de mercados competitivos. Contudo, no final da década de 1970 iniciou-se a incorporação de questôes como economias de escala e competição imperfeita nesses modelos, como um desenvolvimento da teoria de comércio internacional. Tal desenvolvimento ficou conhecido como "Nova Teoria de Comércio Internacional". Krugman (1979) e Lancaster (1979) iniciaram a discussão envolvendo competição monopolística, economias de escala e diferenciação de produtos, no estudo de questôes do comércio internacional. A partir dos trabalhos de Krugman e Lancaster, diversos autores procuraram incorporar economias de escala e competição imperfeita nos modelos de equilíbrio geral. ${ }^{2}$

No presente estudo, utiliza-se um modelo básico do tipo aplicado de equilíbrio geral, multirregional e estático. Diferentes pressuposiçóes quanto aos retornos de escala e natureza da competição em diversos mercados são incorporadas ao modelo. $\mathrm{O}$ modelo empírico parte do modelo conhecido como GTAPinGAMS (Rutherford e Paltsev, 2000), desenvolvido a partir do modelo Global Trade Analysis Project - GTAP (GTAP, 2001). O modelo GTAPinGAMS utiliza a base de dados do modelo GTAP, sendo construído como um problema de complementaridade não-linear, em linguagem de programação GAMS (General Algebraic Modeling System (Brooke et al., 1998)). A linguagem GAMS permite o acesso e a modificação tanto da base de dados quanto do modelo básico, o que é essencial para os propósitos da presente pesquisa, uma vez que permite a modificação das pressuposições básicas do modelo GTAP a respeito de retornos constantes de escala e competição perfeita.

Modelos de equilíbrio geral caracterizam a economia de uma forma simplificada, considerando o comportamento dos agentes e mercados. A Figura 1 apresenta as relações entre os agentes econômicos no modelo para uma economia doméstica qualquer, sob as pressuposições de retornos constantes de escala e competição perfeita.

2 Gurgel (2002) apresenta uma revisão da experiência internacional sobre modelos que incorporam economias de escala e competição imperfeita no estudo de políticas de comércio internacional. 


\section{FIGURA I - ESTRUTURA DA ECONOMIA DOMÉSTICA NO MODELO GTAPinGAMS}



Fonte: Rutherford e Paltsev (2000).

A produção agregada de um bem em uma região é composta de uma agregação entre fatores primários e insumos intermediários, que não são substituíveis entre si (função Leontief). O valor adicionado é composto dos fatores primários de produção, e seguem uma função Cobb Douglas, tendo elasticidade de substituição unitária na formação do valor adicionado. A produção agregada é representada por uma função de elasticidade de transformação constante entre bens para exportação e bens para o mercado doméstico. Os bens produzidos para exportação serão adicionados de serviços de transporte e serão distribuídos aos países importadores (esses fluxos não são detalhados na Figura 1). Os bens produzidos para o consumo doméstico são insumos para a oferta doméstica, que é uma agregação Armington entre bens domésticos e um agregado de bens importados. Este agregado de bens importados, por sua vez, é formado pelos bens importados com origem em diferentes países, que são considerados substitutos imperfeitos entre si.

A oferta doméstica é utilizada para o consumo do governo, consumo das famílias e consumo intermediário. Os bens destinados ao consumo intermediário tornamse insumos nos setores produtivos. As famílias e o governo consomem os bens do agregado Armington em uma função Cobb Douglas. Os consumos do governo e das famílias, bem como a formação de bens de capital, vão compor os gastos do agente representativo que, por sua vez, obtém sua renda como receita dos impostos e venda 
dos fatores primários. Esses fatores são empregados nos setores produtivos. Os fatores de produção capital, trabalho qualificado e trabalho não-qualificado possuem perfeita mobilidade entre setores dentro de um mesmo país, porém são imóveis entre diferentes países, mesmo após a formação de acordos comerciais. O fator terra é específico aos setores agropecuários. Os mercados de fatores foram modelados sem rigidez, ou seja, considera-se o pleno emprego, incluindo os mercados de trabalho.

A elasticidade de transformação entre produção para o mercado doméstico e para exportação é representada por $\eta$. $\sigma_{\mathrm{dm}}$ é a elasticidade de substituição Armington entre produtos domésticos e importados e $\sigma_{\mathrm{mm}}$ é a elasticidade de substituição Armington entre bens importados de diferentes países. O modelo GTAPinGAMS assume os valores de: $\eta=8, \sigma_{\mathrm{dm}}=4$, e $\sigma_{\mathrm{mm}}=8 .{ }^{3}$ Esses valores podem ser facilmente alterados na estrutura do GAMS.

O modelo GTAPinGAMS utiliza a syntax do algoritmo MPSGE (Modeling Programing System for General Equilibrium), desenvolvida por Rutherford (1999). O MPSGE representa um modelo de equilíbrio geral por meio de blocos de equações de funções de produção, de demanda e restrições específicas. Uma vez descritos os blocos do modelo, o MPSGE transforma essas informações em equações algébricas que são processadas no software GAMS. As equações geradas caracterizam condições de lucro zero para a produção, equilíbrio entre oferta e demanda nos mercados e definição da renda para os consumidores do modelo, na forma de um problema de complementaridade mista (mixed complementary problem - MCP (Rutherford, 1995)). ${ }^{4}$

O modelo assume retornos constantes e competição perfeita em todos os processos produtivos e mercados. Devido aos objetivos da pesquisa, foram incluídas pressuposições de economias de escala e competição imperfeita para alguns setores da economia em todas as regióes explicitamente representadas. Economias de escala são caracterizadas pela adição de uma parcela de custo fixo no custo de produção das firmas de uma indústria. Competição imperfeita é acrescentada considerando-se que as firmas

3 Harrison et al. (2001), estudando opções de políticas comerciais para o Chile, assumem diferentes valores de elasticidade de substituição, considerando como apropriados os valores de 30 e de 15 , respectivamente, para $\sigma_{\mathrm{mm}} \mathrm{e} \sigma_{\mathrm{dm}}$, tendo 8 e 4 como os menores valores no seu modelo. Esses autores citam estudos conduzidos por Reidel (1988) e Athukorala e Reidel (1994), que afirmam que as elasticidades da demanda não são estatisticamente diferentes de infinito quando o modelo está adequadamente especificado. De maneira simplificada, a elasticidade $\sigma_{\mathrm{mm}}$ significa que se um país tentasse aumentar em $1 \%$ os preços de seus produtos no mercado internacional em relação a uma média de importações agregadas, as importações com origem nesse país sofreriam um declínio de $8 \%$ em relação ao agregado de importações. Análises de sensibilidade foram conduzidas alterando os valores de $\sigma_{\mathrm{mm}} \mathrm{e} \sigma_{\mathrm{dm}}$, evidenciando que as magnitudes dos resultados são diretamente proporcionais aos valores das elasticidades, mas os impactos mantêm, em geral, as mesmas direções e proporções relativas. Alguns resultados dessa análise sobre os impactos de bem-estar encontram-se no Anexo.

4 Mais detalhes sobre as equações do modelo geradas pelo algoritmo MPSGE podem ser encontradas em Rutherford e Paltsev (2000). Gurgel e Campos (2003) apresentam a formulação matemática do modelo sob retornos constantes e competição perfeita. 
imperfeitamente competitivas determinam preços por meio de uma regra de markup ao estilo Cournot.

A presença de economias de escala torna necessário um número limitado de firmas no mercado. Pressupõe-se um número representativo de firmas que possuem características idênticas entre si. A produção total de uma indústria pode ser considerada como a produção por firma multiplicada pelo número de firmas. Admite-se, ainda, que o produto produzido com economias de escala é homogêneo.

O grau de economia de escala pode ser determinado pelo parâmetro de escala, que expressa o nível da escala inexplorada na indústria por meio da relação entre custo médio e custo marginal (Equação 1).

$$
s_{i r}=\mathrm{Cme}_{i r} / \mathrm{Cmg}_{\mathrm{ir}}
$$

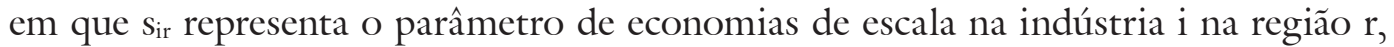
$\mathrm{Cme}_{\text {ir }}$ representa o custo médio e Cmg ir representa o custo marginal.

Quanto maior for o parâmetro de escala $\left(\mathrm{s}_{\mathrm{ir}}\right)$, maior será o grau de economias de escala não exploradas na indústria. A partir da Equação l, assumindo o custo marginal como constante, nota-se que o grau de economia de escala inexplorada diminui quando a firma expande a produção, uma vez que o custo médio decresce devido à presença dos custos fixos.

Na presença de economias de escala, as firmas não podem mais seguir a regra de otimização de preço igual ao custo marginal, uma vez que o custo marginal agora é menor que o custo médio. Desta forma, a presença de economias de escala leva naturalmente à existência de competição imperfeita na economia. Em competição imperfeita as firmas passam a adotar uma regra de formação de preço, deixando de ser tomadoras de preço. A pressuposição usualmente adotada na literatura a respeito da determinação de preços pelas firmas é de comportamento oligopolístico de Cournot, aplicando um markup de preço sobre custos marginais. A expressão para o grau de markup ótimo da firma é representada pela Equação 2.

$$
m k_{i r}=\frac{P D_{i r}-C m g_{i r}}{P D_{i r}}=\frac{1}{n f_{i r} \varepsilon_{i r}}
$$

em que $m_{\mathrm{ir}}$ representa o markup de preço sobre custo marginal na indústria i e região $\mathrm{r}$, como uma proporção do preço doméstico $\mathrm{PD}_{\mathrm{ir}},{ }^{5} \mathrm{nf}_{\mathrm{ir}}$ representa o número de firmas na indústria e $\varepsilon_{\text {ir }}$ representa a elasticidade-preço da demanda pelo bem i na região $r$.

5 Para facilitar a representação matemática, apresenta-se o markup apenas sobre os preços domésticos, $\mathrm{PD}_{\mathrm{ir}}$. Porém, como o markup é aplicado também sobre a produção destinada à exportação, deve-se levar 
A maior dificuldade na formulação de modelos de equilíbrio geral, considerando oligopólio de Cournot, diz respeito à definição da elasticidade-preço da demanda a ser usada para determinar o markup ótimo na Equação 2. Hoffman (2001) discute que usualmente utilizam-se as elasticidades-preço da demanda marshaliana ${ }^{6}$ como uma aproximação. Esse autor deriva tais elasticidades para um modelo de equilíbrio geral que incorpora economias de escala e competição imperfeita, considerando comportamento oligopolista de Cournot, redefinindo a fórmula de markup como na Equação 3.

$$
m k_{i r}=\frac{1}{n f_{i r}\left[\sigma_{d m}+\theta_{i r}^{D}\left(\varepsilon_{i r}^{A}-\sigma_{d m}\right)\right]}
$$

em que $\sigma_{\mathrm{dm}}$ é a elasticidade de substituição Armington entre bens domésticos e importados, $\theta_{\mathbf{r}}^{\text {D }}$ é a parcela de participação do bem composto Armington i de origem doméstica no total demandado do bem composto i na região $r$, e $\varepsilon_{\mathrm{r}}^{\mathrm{A}}$ é a elasticidadepreço da demanda pelo bem composto Armington.

O denominador da Equação 3 representa a elasticidade da demanda percebida pelas firmas no mercado. À medida que choques são aplicados ao modelo, preços e quantidades são alterados, alterando também o valor da elasticidade-preço, uma vez que a parcela de participação dos bens domésticos no agregado Armington e a elasticidadepreço da demanda do bem composto Armington são alteradas. Como o composto Armington é consumido em três mercados diferentes (consumo intermediário, consumo do agente privado representativo e consumo do governo), sua elasticidade-preço é calculada como uma média ponderada entre as elasticidades nos diferentes mercados, de acordo com a parcela consumida em cada mercado.

$\mathrm{Na}$ aplicação do modelo oligopolista de Cournot pressupõe-se a livre entrada e saída de firmas no mercado, o que conduz a lucros normais pelas firmas. ${ }^{7}$ Tal pressuposição tem sido bastante utilizada nos trabalhos que incorporam economias de escala e competição imperfeita, como em Markusen et al. (1995). A partir disso, a entrada e saída de firmas ocorre até o ponto em que o preço de mercado se iguala ao custo médio da firma.

As relações descritas anteriormente são incorporadas no modelo GTAPinGAMS original, de forma a caracterizar economias de escala e competição imperfeita. Tal

em conta que o modelo considera também uma equação similar à equação 25 , porém com $\mathrm{PX}_{\text {ir }}$ no lugar de $P D_{\text {ir. }}$.

6 De acordo com Hoffman (2001), tais elasticidades introduziriam um erro no cálculo do número de firmas, uma vez que estas não consideram todas as inter-relações que ocorrem num modelo de equilíbrio geral. As elasticidades de equilíbrio geral apropriadas para tais estudos, porém, não podem ser descritas de forma explícita, sendo possível apenas o cálculo dessas a partir de métodos numéricos.

7 Tal pressuposição significa que a única barreira ao movimento de firmas é dada pelos custos fixos. Acredita-se que tal pressuposição esteja mais de acordo com a realidade para um grande número de indústrias do que a pressuposição de barreiras intransponíveis à entrada de novas firmas. 
incorporação é feita por meio de um artifício lógico de quebrar o setor com economias de escala em dois subsetores, um que utiliza os custos variáveis para produzir o nível de atividade do setor e outro que utiliza os custos fixos para determinar um nível de atividade que corresponde ao número representativo de firmas no setor. A ligação entre os dois subsetores é dada pelo markup, cobrado sobre o preço do bem produzido a partir dos insumos e fatores variáveis, e destinado a compor a renda de um novo agente representativo, chamado no modelo de oligopolista. Esse agente usa toda a receita advinda do markup para absorver completamente o "bem" gerado pela combinação dos insumos e fatores fixos, garantindo, com isso, o lucro zero em cada setor e representando a livre entrada e saída de firmas. Portanto, existe uma função de custo unitário (gerada a partir da minimização das despesas com insumos e fatores sujeita à tecnologia de produção para produzir uma unidade de produto) para o componente variável dos custos e uma para o componente fixo dos custos. Desta forma, as propriedades de homogeneidade em preços das funções CES de produção e de custos são mantidas.

A Tabela 1 apresenta uma descrição de variáveis e parâmetros do modelo, importantes para representar as mudanças na álgebra do modelo quando da incorporação de economias de escala e competição imperfeita.

\section{TABELA I-PARÂMETROS E VARIÁVEIS DO MODELO PARA REPRESENTAR AS PRINCIPAIS MUDANÇAS ALGÉBRICAS NECESSÁRIAS À INCORPOR AÇÃO DE ECONOMIAS DE ESCALA E COMPETIÇÃO IMPER FEITA}

\begin{tabular}{|c|c|}
\hline Parâmetros e variáveis* & Descrição \\
\hline $\mathrm{AF}_{\text {fir }}$ & Demanda unitária do fator f pelo setor i \\
\hline$A X_{i r}$ & Oferta unitária de exportação do setor i \\
\hline$A D_{\text {ir }}$ & Oferta unitária doméstica do setor i \\
\hline$P D_{\text {ir }}$ & Preço do bem doméstico i \\
\hline $\mathrm{PX}_{\mathrm{ir}}$ & Preço de exportação do bem i \\
\hline $\mathrm{PA}_{\text {lir }}$ & Preço do bem composto Armington i com destino ao mercado de bens intermediários \\
\hline $\mathrm{PF}_{\mathrm{fr}}$ & Preço do fator $f$ \\
\hline$Y_{\text {ir }}$ & Produção agregada do setor i \\
\hline$M_{\text {ir }}$ & Agregação de importações do bem i com destino à região $r$ \\
\hline$A_{\text {lir }}$ & Agregação Armington de bens intermediários domésticos e importados do setor i \\
\hline $\mathrm{RA}_{r}$ & Renda do agente privado representativo \\
\hline $\mathrm{N}_{\mathrm{ir}}$ & Número de firmas no setor $\mathrm{i}$ \\
\hline $\mathrm{RO}_{\mathrm{ir}}$ & Renda do agente representativo oligopolista no setor i \\
\hline $\mathrm{Pcf}_{\mathrm{ir}}$ & Preço do bem representativo produzido pelos custos fixos no setor i \\
\hline $\mathrm{MK}_{\mathrm{ir}}$ & Markup de preço sobre custo marginal no setor i \\
\hline $\mathrm{Va}_{\text {lir }}$ & Oferta Armington destinada ao mercado d no setor i \\
\hline$e^{e v o a} a_{f r}$ & Renda total do fator de produção f \\
\hline vafm $_{\text {jir }}$ & Agregado de insumos intermediários do setor j utilizado no setor i \\
\hline & Parcela de custos fixos nos custos totais do setor i \\
\hline$n_{\text {ir }}$ & Número representativo de firmas no setor i no equilíbrio inicial \\
\hline $\mathrm{cmg}_{\mathrm{ir}}$ & Parcela de custo variável nos custos totais do setor i \\
\hline
\end{tabular}

* As variáveis são representadas com iniciais maiúsculas, enquanto os parâmetros são representados com letras minúsculas. O subscrito r representa a região, e j representa setores. 
A Figura 2 representa a estrutura do setor produtivo com economias de escala e a relação deste com o setor de custo fixo e o agente oligopolista. O setor produtivo utiliza agora uma menor proporção dos fatores primários e dos insumos intermediários. Esta proporção é representada pelo parâmetro $\mathrm{cmg}_{\text {ir }}$ multiplicado pelas variáveis correspondentes à demanda de fatores primários e demanda intermediária. O novo setor no modelo, setor $\mathrm{N}_{\mathrm{ir}}$, utiliza uma proporção dos fatores primários e insumos intermediários, considerados custos fixos, e produz uma commoditie, representada por $\mathrm{Pcf}_{\mathrm{ir}}$, que é comprada pelo agente oligopolista, representado por $\mathrm{RO}_{\text {ir }}$. $\mathrm{O}$ fator $\mathrm{cf}_{\text {ir }}$ representa a proporção dos custos fixos aplicada aos fatores primários e insumos intermediários. A soma de $\mathrm{cmg}_{\text {ir }} \mathrm{e}_{\mathrm{ir}}$ deve ser igual a $\mathrm{l}$. O agente oligopolista recebe como receita o markup, que é pago pelo setor $\mathrm{Y}_{\mathrm{ir}}$, de forma semelhante a um imposto ad valorem.

\section{FIGURA 2 - ESTRUTURA DO SETOR PRODUTIVO EM ECONOMIA DE ESCALA E COMPETIÇÃO IMPERFEITA}

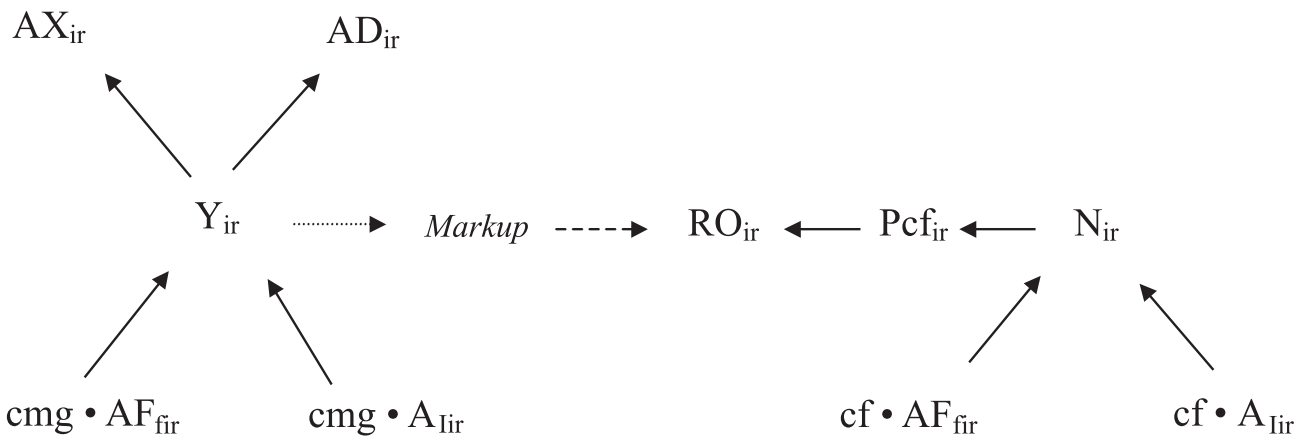

A receita do markup recebida pelo oligopolista deve ser igual ao valor pago pela commoditie produzida a partir dos custos fixos. Isto significa que a renda líquida do oligopolista se iguala a zero, devido à pressuposição de livre entrada e saída de firmas no mercado.

A alteração algébrica do modelo original GTAPinGAMS para incorporar as pressuposições de economias de escala e competição perfeita consiste em acrescentar o novo subsetor e o novo agente, para cada setor com economias de escala, e as relações que determinam o comportamento desses.

As funções de demanda e oferta unitárias descritas no quadro acima são representadas na forma de funções (de parcelas calibradas) de elasticidade de substituição constante (CES) e de transformação constante (CET), respectivamente, cujos argumentos são 
as variáveis de preços dos fatores e dos bens e os preços de referência no equilíbrio inicial, bem como os valores iniciais dos bens e fatores demandados e ofertados.

A condição de lucro zero aplicada aos setores produtivos, sob competição perfeita e retornos constantes, pode ser representada pela equação 4 (os impostos foram omitidos para facilitar a representação). Essa equação mostra a necessidade de igualar os custos ao valor da produção.

$$
\sum_{j}\left[\operatorname{vafm}_{j i r} P A_{I j r}\right]+\sum_{f}\left[A F_{f i r} P F_{f r}\right]=\left(P D_{i r} A D_{i r}+P X_{i r} A X_{i r}\right)
$$

Para acrescentar economias de escala e competição imperfeita, a equação acima deve ser quebrada em duas novas equações. A primeira delas, a equação 5 , representa o uso dos insumos variáveis, pela multiplicação do fator $\mathrm{cmg}$ ir (note que a omissão deste não altera a equação) e a introdução do markup na forma de um imposto sobre o valor da produção. A igualdade desta relação é garantida ao considerar, no equilíbrio inicial, que os preços $P A$ e $P F$ são calibrados de forma a incluir a diferença entre preços e custo marginal. A equação 6 mostra a equação correspondente ao uso dos insumos fixos para produzir a variável $P c f_{i r}$ que será "consumida" pelo oligopolista.

$$
\begin{aligned}
& \sum_{j}\left[\left(c m g_{i r} \cdot v a f m_{j i r}\right) P A_{i j r}\right]+\sum_{f}\left[c m g_{i r} \cdot A F_{f i r} P F_{f r}\right]= \\
& c m g_{i r}\left(P D_{i r} A D_{i r}+P X_{i r} A X_{i r}\right)\left(1-M K_{i r}\right) \\
& \sum_{j}\left[\left(\frac{c f_{i r}}{\bar{n}_{i r}} \cdot v a f m_{j i r}\right) P A_{j j r}\right]+\sum_{f}\left[\frac{c f_{i r}}{\bar{n}_{i r}} \cdot A F_{f i r} P F_{f r}\right]=\frac{c f_{i r}}{\bar{n}_{i r}} P c f_{i r}
\end{aligned}
$$

No modelo com economias de escala deve-se acrescentar uma equação correspondente ao equilíbrio entre oferta e demanda para cada subsetor, representando o bem produzido a partir dos custos fixos, como na equação 7.

$$
\frac{c f_{i r}}{\bar{n}_{i r}} P c f_{i r}=R O_{i r}
$$

Com economias de escala, as equações de equilíbrio entre oferta e demanda devem ser modificadas para os fatores e insumos utilizados na produção do bem sob economias de escala. As equações 8 e 9 mostram tal equilíbrio no modelo sob retornos constantes, e as equações 10 e 11 no modelo com economias de escala. 


$$
\begin{aligned}
& v a_{I i r} A_{I i r}=\sum_{j}\left(v a f m_{i j r} Y_{j r}\right) \\
& \operatorname{evoa}_{f r}=\sum_{i}\left(A F_{f i r} Y_{i r}\right) \\
& v a_{I i r} A_{I i r}=\sum_{j}\left(c m g_{j r} v a f m_{i j r} Y_{j r}\right)+\sum_{j}\left(c f_{j r} v a f m_{i j r} \frac{N_{j r}}{\bar{n}_{j r}}\right) \\
& \operatorname{evoa}_{f r}=\sum_{i}\left(c m g_{i r} A F_{f i r} Y_{i r}\right)+\sum_{i}\left(c f_{i r} A F_{f i r} \frac{N_{i r}}{\bar{n}_{i r}}\right)
\end{aligned}
$$

No modelo com economias de escala deve-se ainda acrescentar a equação de esgotamento da renda do monopolista (equação 12). Por fim, deve-se acrescentar uma equação para cada setor com economias de escala determinando o markup ótimo, como na equação 13, que é a mesma fórmula representada na equação 3.

$$
\begin{aligned}
& R O_{i r}=M K_{i r} c m g_{i r}\left(P D_{i r} A D_{i r}+P X_{i r} A X_{i r}\right) Y_{i r} \\
& M K_{i r} N_{i r}\left[\sigma_{d m}+\theta_{i r}^{D}\left(\varepsilon_{i r}^{A}-\sigma_{d m}\right)\right]=1
\end{aligned}
$$

Essas são as principais modificações na álgebra do modelo para alterar as pressuposições originais de retornos constantes e competição perfeita para economias de escala e oligopólio de Cournot.

Os parâmetros iniciais de markup, número de firmas representativas na indústria, nível de custos fixos, preço de oligopólio, parâmetro de escala e elasticidade da demanda das firmas em competição imperfeita são determinados de forma a manter o equilíbrio inicial do modelo, pelo processo de calibração.

A Figura 3 exemplifica graficamente um possível comportamento do modelo para uma firma qualquer na presença de economias de escala e oligopólio de Cournot com livre entrada e saída de firmas. Para uma situação inicial de equilíbrio de mercado, a firma determina o nível de preço $\left(\mathrm{p}^{0}\right)$ a partir da regra de markup, que é uma função da elasticidade da demanda. A partir do preço e da curva de demanda, é estabelecido o nível de produção $\left(\mathrm{Y}^{0}\right)$ ofertado pela firma oligopolizada. Pode-se notar que a curva de custo médio, representada por uma linha pontilhada, determina níveis de custos menores à medida que a produção da firma aumenta. $\mathrm{O}$ equilíbrio em nível da in- 
dústria requer a livre entrada e saída de firmas até o lucro zero, de forma que ocorre a tangência entre a curva de demanda da firma $\left(\mathrm{D}^{0}\right)$ e a sua curva de custo médio $\left(\mathrm{Cme}^{0}\right)$. O equilíbrio geral surge quando todas as firmas oligopolistas encontram o equilíbrio descrito acima, as indústrias com retornos constantes apresentam lucros iguais aos seus custos, os mercados de produtos e fatores não possuem excesso ou escassez e as rendas dos agentes se igualam às suas despesas.

Supondo uma redução das barreiras comerciais para a indústria doméstica exportadora, poderia ocorrer uma mudança na inclinação e posição da curva de demanda. $\mathrm{Na}$ ausência de barreiras à entrada de novas firmas no mercado, a possibilidade de lucros positivos atrai novas firmas para a indústria, reduzindo a demanda pelo produto de uma firma representativa, deslocando a sua curva de demanda para baixo. O novo equilíbrio de mercado será estabelecido quando o lucro total na indústria for reduzido a zero, o que ocorre quando a curva de demanda de cada firma tangencia sua curva de custo médio, determinando, no exemplo da Figura 3, um nível de preços menor $\left(\mathrm{p}^{\mathrm{l}}\right)$ e um nível de produção maior $\left(\mathrm{Y}^{\mathrm{l}}\right)$.

FIGURA 3 - DIMINUIÇÃO DAS BARREIRAS COMERCIAIS PARA UMA FIRMA EXPORTADORA NO MODELO COM ECONOMIAS DE ESCALA E OLIGOPÓLIO DE COURNOT COM LIVRE ENTRADA E SAÍDA DE FIRMAS

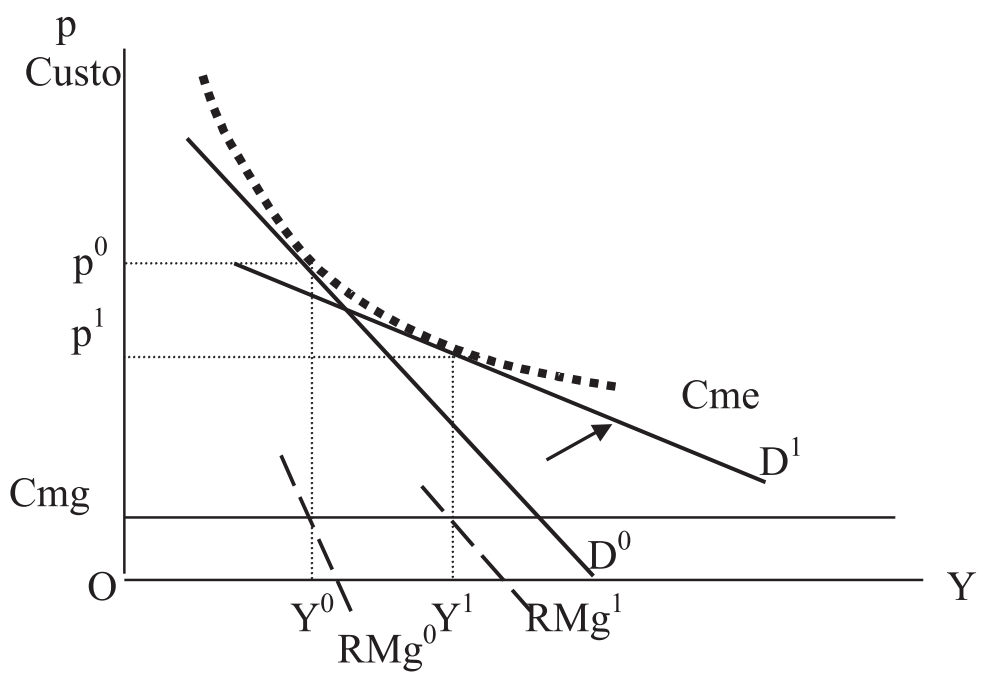

O aumento da demanda promovido pela abertura comercial permite a expansão da produção pelas firmas, com o aproveitamento de economias de escala, à medida que a curva de custo médio é percorrida para a direita, e redução do markup de preço sobre custo marginal. A partir dessa discussão, na presença de economias de escala e competição imperfeita, as modificações incorporadas no modelo devem trazer resultados 
diferentes comparativamente ao modelo tradicional de competição perfeita e retornos constantes. Uma maior abertura comercial para setores tradicionalmente exportadores deve promover uma expansão da produção mais intensa quando se consideram economias de escala, uma vez que o aumento de preços internacionais deve estimular o aumento da produção e o aproveitamento de economias de escala não realizadas. Para setores importadores, porém, a redução das restrições de comércio internacional deve acirrar a concorrência entre produtos domésticos e importados, diminuindo a produção doméstica e aumentado o grau de economias de escalas inexploradas e a diferença entre preços e custo marginal.

Contudo, como destacado por Devarajan e Rodrik (1991), o livre movimento de entrada e saída de firmas no mercado pode trazer a expansão da produção e ganhos de economias de escala, mesmo para aqueles setores importadores. Isto ocorreria a partir da redução do número de firmas domésticas devido à abertura comercial, o que permitiria a expansão da produção e a realização de economias de escala nas firmas que conseguem permanecer no mercado. Este efeito é conhecido como racionalização da indústria, e indica uma maior produtividade e ganhos de escala à medida que as firmas percorrem suas curvas de custo médio. Podem ocorrer ainda ganhos por meio do efeito pró-competitivo, que se dá pela erosão do poder de mercado das firmas nacionais, devido a uma maior competição. Em tal situação, a elasticidade-preço da demanda percebida pelas firmas domésticas aumenta, e a curva de receita marginal desloca-se para a direita, o que pode determinar preços de equilíbrio menores para níveis mais altos de produção.

Pode-se perceber, portanto, que o efeito líquido final nos setores na presença de economias de escala e competição imperfeita é de difícil previsão, existindo a possibilidade de maiores expansões na produção dos setores exportadores, enquanto as firmas nos setores importadores podem sofrer tanto contrações como expansões da produção. Se tais efeitos setoriais são ambíguos, deve-se esperar menor previsibilidade ainda dos efeitos de bem-estar para um país como um todo. Os resultados comumente encontrados na literatura são de que os ganhos de bem-estar são maiores, ou as perdas de bem-estar são mais expressivas, quando se incorporam economias de escala e competição imperfeita em modelos de equilíbrio geral.

\subsection{Dados Originais do GTAP, Simulaçôes e Calibração do Modelo}

O modelo GTAPinGAMS permite a agregação de mercadorias e regiões de acordo com os interesses da pesquisa. Utilizou-se a versão 5 do GTAP, que representa a economia mundial para o ano de 1997. Optou-se pela agregação dos dados originais do 
GTAP5 em 9 regiões e 10 mercadorias diferentes (Quadro 1), procurando caracterizar os principais setores da economia. ${ }^{8}$

\section{QUADRO I-AGREGAÇÕES DO GTAP: REGIÕES E SETORES}

\begin{tabular}{|ll|}
\hline Regiões & \multicolumn{1}{c|}{ Mercadorias/setores } \\
\hline 1. Brasil & 1. Agropecuária \\
2. Argentina & 2. Indústria extrativa mineral \\
3. Uruguai & 3. Energia' \\
4. EUA & 4. Agroindústria ${ }^{2}$ \\
5. Canadá & 5. Têxteis e calçados \\
6. México & 6. Indústria da madeira, papel e derivados \\
7. Resto da América Latina & 7. Indústrias químicas, da borracha e plásticos \\
8. União Européia & 8. Metais \\
9. Resto do Mundo & 9. Manufaturados \\
& 10. Serviços \\
\hline
\end{tabular}

1 Agrega os setores de extração e refino de petróleo e carvão, geração e distribuição de energia elétrica, gás e água;

2 Agrega todas as indústrias alimentícias processadoras de produtos da agropecuária;

3 Agrega os setores de metalurgia, siderurgia e outros metais;

4 Agrega os setores industriais, não incluídos anteriormente: veículos e partes, equipamentos de transporte, eletrônicos, maquinaria e equipamentos, e outros manufaturados.

Fonte: Base de dados do GTAP.

A Tabela 2 apresenta as tarifas médias de importação por mercadoria, aplicadas nas regiôes explicitamente representadas no modelo, de acordo com a base de dados do GTAP. 9 O padrão de proteção observado é de menores níveis tarifários no comércio de bens da agropecuária e da agroindústria nos países do MERCOSUL, enquanto os países e regiões desenvolvidas possuem os menores níveis de proteção comercial nos setores industriais não ligados ao agronegócio. O Brasil apresenta as maiores tarifas no setor denominado manufaturas, em comparação com as demais regiões e países do modelo.

8 Mais detalhes sobre os setores e regiões originais do GTAP podem ser vistos na documentação do GTAP, disponível no site oficial: http://www.agecon.purdue.edu/gtap.

9 A base de dados utilizada considera, em geral, apenas as barreiras tarifárias existentes entre os países. Tarifas específicas aparecem na base de dados do GTAP como tarifas ad valorem. As barreiras não-tarifárias não foram consideradas na base de dados do GTAP, e no presente trabalho, pela dificuldade de quantificar essas barreiras. Considerar a eliminação das barreiras tarifárias já seria um grande avanço em termos de negociações comerciais. Desta forma, a eliminação de barreiras não-tarifárias aplicadas a esses bens deveria promover ganhos comerciais mais pronunciados para os países do MERCOSUL do que os observados no presente estudo. 
TABELA 2 - TARIFAS DE IMPORTAÇÃO (MÉDIAS PONDERADAS EM \%) PARA AS REGIOEES E SETORES EXPLICITAMENTE REPRESENTADOS NO MODELO, 1997

\begin{tabular}{lrrrrrrrrr}
\hline Setores & Brasil & Argentina & Uruguai & EUA & Canadá & México & $\begin{array}{c}\text { Resto da } \\
\text { Am. Latina }\end{array}$ & $\begin{array}{r}\text { União } \\
\text { Européia }\end{array}$ & $\begin{array}{r}\text { Resto do } \\
\text { Mundo }\end{array}$ \\
& & & & & & & & & \\
Agropecuária & 7,84 & 7,91 & 9,12 & 10,60 & 3,27 & 17,22 & 10,82 & 10,47 & 32,54 \\
Extrativa mineral & 7,50 & 8,82 & 13,09 & 5,23 & 3,79 & 12,27 & 11,57 & 2,43 & 6,86 \\
Energia & 3,51 & 0,36 & 0,17 & 0,24 & 0,77 & 6,16 & 7,50 & 0,63 & 3,37 \\
Agroindústria & 16,66 & 15,93 & 18,36 & 10,93 & 29,53 & 31,75 & 16,90 & 37,45 & 35,22 \\
Têxteis e calçados & 18,24 & 18,72 & 18,06 & 12,84 & 17,70 & 20,94 & 17,86 & 10,42 & 15,11 \\
Madeira, papel e der. & 9,51 & 13,28 & 13,56 & 1,69 & 4,17 & 8,30 & 10,65 & 2,76 & 7,45 \\
Quím., plást. e borr. & 9,25 & 9,94 & 10,34 & 3,52 & 4,71 & 9,01 & 9,10 & 4,70 & 8,09 \\
Metais & 12,20 & 14,14 & 12,44 & 3,04 & 3,68 & 9,70 & 9,96 & 2,57 & 7,53 \\
Manufaturados & 19,65 & 15,95 & 11,05 & 1,92 & 3,00 & 10,40 & 11,84 & 3,86 & 6,90 \\
Serviços & - & - & - & - & - & - & 2,22 & - & 0,25 \\
\hline
\end{tabular}

Fonte: Base de dados do GTAPinGAMS.

A partir dessas considerações, serão simulados sete cenários alternativos de política comercial. Os cenários contemplam reduções tarifárias multilaterais, eliminação de impostos às exportações e formação de blocos regionais. Dessa forma, espera-se captar as diferenças de resultados de políticas comerciais diversas sob pressuposições alternativas quanto aos retornos de escala e natureza da competição. O Quadro 2 apresenta uma breve descrição dos cenários simulados. ${ }^{10}$

Os dois primeiros cenários, formação do MERCOSUL e eliminação dos impostos às exportações no Brasil, visam preparar a base de dados para os próximos cenários, uma vez que os dados do GTAP5 não consideram o MERCOSUL como consolidado, bem como apresentam os impostos às exportações praticados no Brasil antes da Lei Kandir de 1996. O MERCOSUL é aplicado via a eliminação completa das tarifas comerciais entre os países participantes deste acordo explicitamente representados no modelo: Brasil, Argentina e Uruguai.

O terceiro cenário simula uma redução de $50 \%$ nas tarifas às importações em todas as regióes do modelo, nos moldes de um acordo ao nível da Organização Mundial de Comércio (OMC). Em termos práticos, este cenário poderia ser interpretado como um resultado otimista das negociações da Rodada do Milênio.

10 Os cenários aqui simulados não pretendem ser tratamentos rigorosos das políticas comerciais em questão, apenas visam atender ao objetivo principal do trabalho, de avaliar os efeitos de políticas comerciais sob pressuposições alternativas quanto ao comportamento dos mercados. 


\section{QUADRO 2 - CENÁRIOS SIMULADOS}

\begin{tabular}{|c|c|}
\hline Cenário & Descrição \\
\hline 1 & $\begin{array}{l}\text { Formação do MERCOSUL (eliminação das tarifas às importações entre Brasil, Argentina e } \\
\text { Uruguai). }\end{array}$ \\
\hline 2 & Eliminação dos impostos às exportações brasileiras. \\
\hline 3 & $\begin{array}{l}\text { Liberalização comercial multilateral (redução de } 50 \% \text { das tarifas às importações em todos os países } \\
\text { e regiões do modelo). }\end{array}$ \\
\hline 4 & $\begin{array}{l}\text { Formação da ALCA (eliminação das tarifas às importações entre os países e regiões dentro das } \\
\text { Américas). }\end{array}$ \\
\hline 5 & Formação da ALCA, com exceções para produtos da agropecuária e da agroindústria. \\
\hline 6 & $\begin{array}{l}\text { Formação de um acordo de livre comércio entre MERCOSUL e UE (eliminação das tarifas às impor- } \\
\text { tações entre os países e regiões do MERCOSUL e da UE). }\end{array}$ \\
\hline 7 & $\begin{array}{l}\text { Formação de um acordo de livre comércio entre MERCOSUL e EU, com exceções para produtos da } \\
\text { agropecuária e da agroindústria. }\end{array}$ \\
\hline
\end{tabular}

O quarto cenário simula a formação da Área de Livre Comércio das Américas (ALCA), pela completa eliminação de tarifas às importações entre os países do continente americano. Por se tratar de uma situação fictícia e bastante otimista diante do teor das negociações atuais, procurou-se simular também a formação da ALCA com exceções na liberalização dos mercados agrícolas e agroindustriais (cenário 5), mantendo-se as tarifas existentes nestes setores e eliminando as tarifas nos setores não ligados ao agronegócio.

O sexto cenário visa obter informações sobre os possíveis resultados de uma integração entre o MERCOSUL e a União Européia (UE), pela eliminação das tarifas às importações entre os países de ambos os blocos. O sétimo cenário também simula a integração entre MERCOSUL e UE, contudo considera que os mercados de produtos agropecuários e da agroindústria são excluídos do acordo, não sofrendo reduçôes tarifárias.

A matriz de insumo-produto da economia brasileira, fornecida para a versão 5 do GTAP, data de 1985. (Walmsley e McDougall, 2001). Foram utilizadas as ferramentas presentes no pacote do software GTAPinGAMS para atualizar os dados originais do GTAP5 para o Brasil, a partir das informaçóes da Matriz de Insumo Produto de 1996. ${ }^{11}$ Os dados de fluxos comerciais e proteção comercial (tarifas às importações e impostos às exportações) do GTAP5 não foram alterados.

Os cenários alternativos são simulados no modelo com retornos constantes de escala e competição perfeita e no modelo com economias de escala e competição imperfeita. No modelo com economias de escala é necessária a determinação de parâmetros iniciais que caracterizem economias de escala e oligopólio, a partir dos quais o modelo

11 Em linhas gerais, o GTAPinGAMS utiliza um algoritmo que resolve um problema de minimização da diferença entre os dados originais do GTAP e uma nova fonte de dados fornecida pelo pesquisador, sujeita à restrição de que os dados de fluxos comerciais e proteção comercial não sejam alterados. 
é calibrado. Neste modelo, apenas os setores da agropecuária, de energia, têxteis e calçados e de serviços foram considerados como de concorrência perfeita e retornos constantes, ${ }^{12}$ enquanto os demais setores foram modelados com economias de escala e competição imperfeita. Foram arbitrados valores iniciais para o parâmetro de escala, e a partir daí determinou-se a porcentagem de participação dos custos marginais no custo total médio e o grau de markup. A partir da calibração do modelo determinou-se o número representativo de firmas no oligopólio de Cournot. ${ }^{13}$

Procurou-se manter níveis aproximados de economias de escala não exploradas para os países da América Latina e níveis menores para os países desenvolvidos. Dessa forma, considera-se que os países em desenvolvimento possuem maior grau de economias de escala não aproveitadas, uma vez que esses países possuem setores industriais menos desenvolvidos.

\section{RESULTADOS}

A Tabela 3 apresenta os impactos dos cenários simulados sobre o bem-estar em todas as regióes do modelo, na forma de variação equivalente, que mede o aumento na utilidade dos consumidores domésticos, em termos de aumento da renda.

O Brasil apresenta impactos positivos de aumento do bem-estar em praticamente todos os cenários simulados, excetuando os cenários de formação da ALCA e do acordo entre MERCOSUL e EU, com exceções na liberalização de produtos da agropecuária e da agroindústria sob retornos constantes. A liberalização comercial multilateral (cenário 3) traz os maiores ganhos de bem-estar para o Brasil, entre os cenários simulados.

Os países parceiros do Brasil no MERCOSUL são os maiores beneficiados com o acordo do MERCOSUL (cenário 1), bem como se beneficiam da eliminação dos impostos às exportações brasileiras (cenário 2). A formação da ALCA (cenários 4 e

5) não traz vantagens aparentes para a Argentina e o Uruguai. Contudo, um acordo

12 Os setores agropecuária, têxteis e calçados e de serviços apresentam estruturas de competição mais próximas da competição perfeita e retornos de escala constantes ou crescentes externos às firmas. O setor de energia é um caso especial, pois a maioria das empresas desses setores possui preços administrados e/ou estão sob o controle do governo. Desta forma, apesar da presença de economias de escala internas às firmas, a competição imperfeita torna-se de difícil caracterização para estes setores.

13 Harris (1984), Roland-Host et al. (1994), entre outros, utilizaram ou estimaram valores de parâmetros de markup e economias de escala similares aos do presente trabalho. Os parâmetros de escala nos países da América Latina são cerca de 6\% a 12\% superiores aos dos países desenvolvidos, dependendo do setor considerado. Como o Resto do Mundo agrega países desenvolvidos e países em desenvolvimento, em geral foram arbitrados valores intermediários para os setores nessa região. Análises de sensibilidade sobre os impactos em bem-estar foram conduzidas alterando os valores destes parâmetros, revelando que a abertura comercial traz maiores ganhos de bem-estar quanto maior for o grau de economias inexploradas, como apresentado no Anexo. 
entre MERCOSUL e UE (cenário 6) traz ganhos para estes países, principalmente para o Uruguai. Porém esses ganhos são revertidos em prejuízos se o agronegócio for excluído deste acordo (cenário 7), o que evidencia a dependência do comércio exterior do Uruguai de vantagens competitivas no setor agropecuário.

A abertura comercial multilateral (cenário 3) traz ganhos maiores para a maioria das demais regiões do modelo do que os demais cenários. Para os EUA, estes ganhos são ligeiramente superiores aos ganhos a serem obtidos com a ALCA (cenário 4), enquanto que para o Canadá a liberalização multilateral traz ganhos mais expressivos do que a ALCA. México e Resto da América Latina, por sua vez, apresentam ganhos maiores com a ALCA do que com a abertura comercial multilateral. A UE apresenta maiores ganhos com a abertura comercial multilateral do que com a formação do acordo entre MERCOSUL e UE (cenário 6). Portanto, pode-se inferir que para a maioria dos países e regiões representados no modelo a estratégia de perseguir reduções de barreiras comerciais no âmbito da OMC, em que todos os setores são contemplados, é melhor do que a formação de acordos comerciais regionais de eliminação de tarifas às importações.

Comparando os resultados dos cenários sob pressuposições alternativas no referente aos retornos de escala e natureza da competição, tem-se que os resultados de bem-estar são, em geral, mais expressivos quando economias de escala e competição imperfeita são consideradas. No caso do Brasil, os ganhos de bem-estar sob economias de escala são cerca de três a quatro vezes superiores aos ganhos sob retornos constantes nos cenários 1, 2, 3 e 6. No caso do cenário 4, de formação da ALCA, os ganhos sob economias de escala são 10 vezes maiores que os ganhos sob retornos constantes. Em alguns cenários, observa-se uma reversão na direção do resultado, como nos cenários 5 e 7 para o Brasil, que apresenta ligeiras perdas de bem-estar sob retornos constantes e ganhos sob economias de escala. O mesmo ocorre para a Argentina nos cenários 4, 5 e 7.

Esses resultados evidenciam que os impactos sobre o bem-estar, mensurados pelos modelos de equilíbrio geral, podem ser bem diferentes em magnitude e até mesmo em sinal de acordo com as pressuposições consideradas sobre o comportamento dos setores. Resultados positivos sob retornos constantes aumentam em magnitude se economias de escala são consideradas. Resultados negativos próximos de zero sob retornos constantes, por sua vez, tendem a se tornar positivos sob economias de escala. A seguir, procura-se apontar as razões que levam a essas diferenças de impactos em bem-estar sob pressuposições alternativas, utilizando para tal os resultados para o Brasil.

A análise de indicadores setoriais de produção, preços e remuneração de fatores permite observar diferenças que explicam os resultados de bem-estar sob pressuposições alternativas no que tange aos retornos de escala e natureza da competição. 


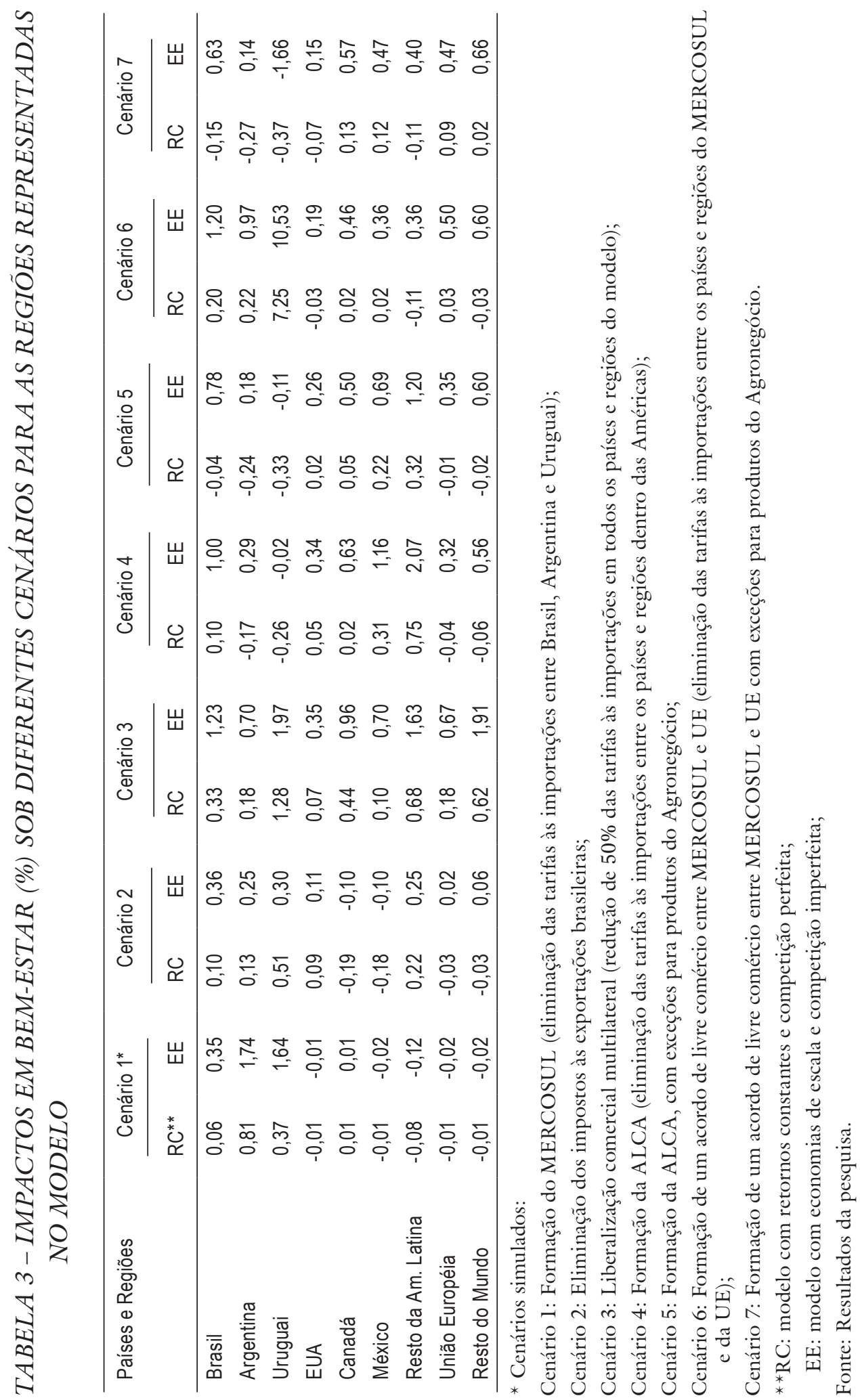


A Tabela 4 apresenta os resultados de variação no valor da produção setorial brasileira advindos dos cenários simulados. As variações no valor da produção revelam o padrão de proteção e de vantagem competitiva do Brasil em relação aos demais países do modelo. No cenário do MERCOSUL (cenário 1) os setores agropecuária e agroindústria apresentam redução na produção e os demais setores industriais apresentam aumentos na produção. Nos demais cenários, a agroindústria, a indústria extrativa mineral e a agropecuária apresentam aumentos no valor da produção. Os setores de químicos, plásticos e borracha e o setor de manufaturados apresentam reduções no valor da produção nos cenários de liberalização comercial, seja na forma multilateral, seja nos acordos regionais, evidenciando a menor capacidade competitiva e maior proteção comercial nestes setores.

Os resultados de variação no valor da produção evidenciam que, com algumas exceções, os aumentos no valor da produção são mais intensos, ou as reduções no valor da produção são menos pronunciadas, sob economias de escala do que sob retornos constantes. Isso significa que os cenários de política comercial simulados permitem o aproveitamento de economias de escala e redução de markup nas indústrias em competição imperfeita, permitindo melhores resultados de variação na produção, e contribuindo para melhores resultados de bem-estar sob essas pressuposições.

Para verificar a hipótese de aproveitamento de economias de escala e redução das distorções de competição imperfeita foram extraídos os resultados sobre mudanças no parâmetro de escala, no markup e no número de firmas nos setores modelados em economias de escala e competição imperfeita no modelo que considera estes fenômenos. Os resultados são apresentados na Tabela 5.

Os valores negativos de mudanças no parâmetro de escala $(s)$, no markup e no número de firmas para praticamente todos os setores em todos os cenários indicam a ocorrência de efeitos de racionalização nessas indústrias, na medida em que o aumento da competição internacional força a saída de firmas menos eficientes nas indústrias do País e redução do markup das firmas sobreviventes, com o aumento da produção e aproveitamento de economias de escala por essas firmas sobreviventes.

Apenas o setor da agroindústria apresenta um aumento no número de firmas, nos cenários 2 a 7, o que indica a ocorrência do efeito pró-competitivo nessa indústria. Por esse efeito, a redução das barreiras comerciais promove o aumento do mercado para as firmas brasileiras, permitindo o aumento da produção e o aproveitamento de economias de escala. Como o modelo permite a entrada e saída de firmas em resposta a lucros positivos, o aumento do mercado estimula a entrada de novas empresas competidoras nessa indústria, forçando cada empresa a reduzir seu markup. 


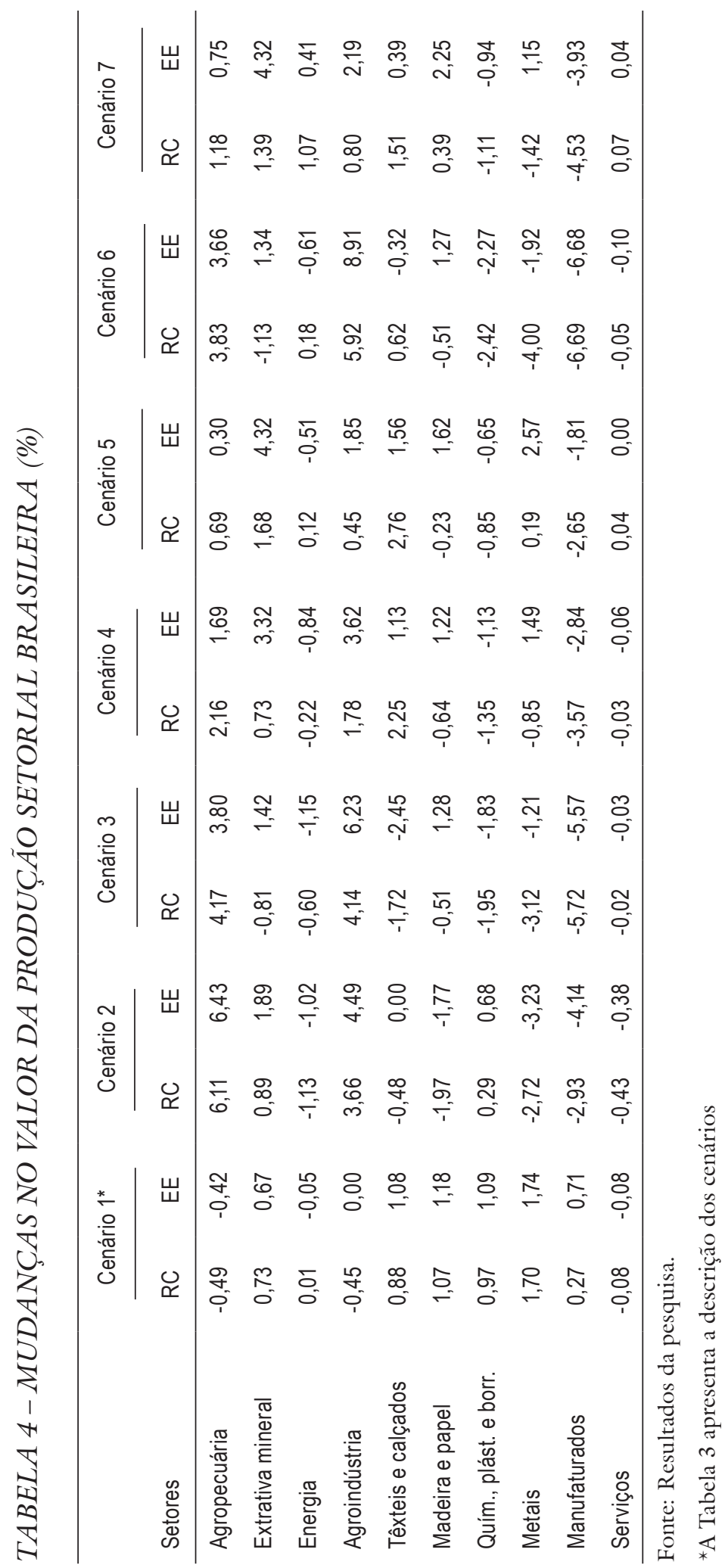




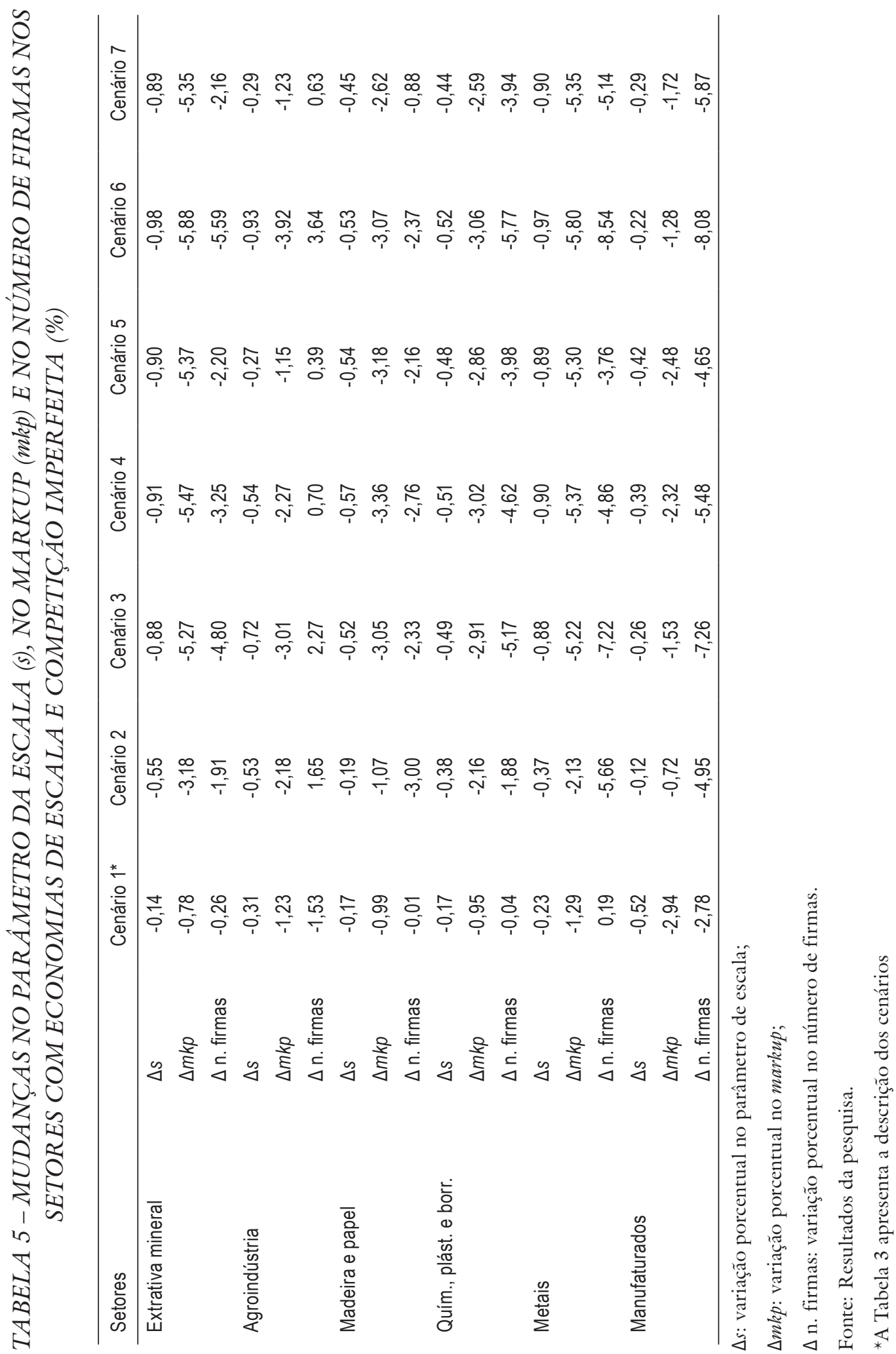


Portanto, os efeitos racionalização e pró-competitivo contribuem para ganhos de bem-estar no País, uma vez que permitem o aproveitamento de economias de escala e redução de markups, com aumento da produção e redução de custo.

A maioria dos cenários simulados mostra uma mudança na distribuição funcional da renda no Brasil, uma vez que muitos setores apresentam resultados negativos de mudanças na produção. Esses resultados refletem a estrutura da proteção comercial brasileira antes da implementação dos cenários, na qual os setores industriais são relativamente mais protegidos no País em comparação com as demais regiões fora do MERCOSUL, enquanto os setores do agronegócio são relativamente menos protegidos no Brasil. Dessa forma, movimentos em direção a uma maior abertura comercial favorecem os setores brasileiros relativamente menos protegidos, e prejudicam aqueles setores com maiores tarifas no equilíbrio inicial. Nota-se, contudo, que apesar da redução no valor da produção de muitos setores os resultados agregados de bem-estar são favoráveis ao País em todos os cenários sob economias de escala e competição imperfeita, devido ao efeito de racionalização nesses setores.

As mudanças nas políticas comerciais simuladas promovem mudanças nos preços internacionais das mercadorias explicitamente representadas no modelo. As mudanças nos preços internacionais promovem reajustes nos fluxos comerciais e produções domésticas de acordo com o padrão de vantagens competitivas de cada região e interações setoriais no modelo de equilíbrio geral. Um dos resultados desses ajustes é observado no preço final das mercadorias para os consumidores de cada região. Menores preços ao consumidor estimulam o aumento no consumo dos bens e, portanto, aumento no bem-estar. A Tabela 6 apresenta os resultados de mudanças porcentuais nos preços ao consumidor no Brasil.

Para a maioria dos cenários e para quase todos os setores ocorre a redução nos preços aos consumidores. Com exceção da agroindústria, os demais setores industriais apresentam reduções de preços em todos os cenários. A agropecuária apresenta aumentos de preços ao consumidor, ainda que reduzidos, em todos os cenários sob retornos constantes e nos cenários 1 e 2 sob economias de escala. Esses resultados ajudam a explicar os ganhos de bem-estar auferidos pelo Brasil nos cenários simulados.

Comparando os resultados dos cenários sob pressuposiçôes alternativas quanto aos retornos de escala, percebe-se claramente que, sob economias de escala e competição imperfeita, as reduções em preços ao consumidor são mais pronunciadas. Como exemplo, o setor de manufaturados sofre reduções de preços ao consumidor no modelo com economias de escala, que são cerca do dobro das reduções de preços no modelo com retornos constantes, para a maioria dos cenários considerados. Essas reduções de preços mais pronunciadas no modelo com economias de escala são consequiência 
do aproveitamento de economias de escala e redução de markups nas indústrias em consideração. Portanto, pode-se concluir que as maiores reduções de preços ao consumidor no modelo de economias de escala e competição imperfeita contribuem para os ganhos de bem-estar mais pronunciados, em comparação com o modelo tradicional de retornos constantes e competição perfeita.

Outro fenômeno que contribui diretamente para os efeitos de bem-estar nos modelos de equilíbrio geral é a mudança na remuneração dos fatores primários de produção, uma vez que essa remuneração é o que define a renda dos consumidores. Aumentos nas remunerações dos fatores indicam aumentos na renda do consumidor, enquanto que reduções nas remunerações dos fatores indicam redução na renda. A Tabela 7 apresenta as variações nas remunerações dos fatores no Brasil, nos cenários simulados.

Todos os cenários simulados provocam aumentos porcentuais nas remunerações dos fatores de produção no Brasil, excetuando o fator terra no cenário l, sob as pressuposições de retornos constantes e competição perfeita. Esse resultado particular pode ser explicado pela queda na produção do setor agropecuário, no qual o fator terra é utilizado exclusivamente, quando da formação do MERCOSUL. Nesse e nos demais cenários, as reduções das barreiras comerciais estimulam o aumento do uso dos fatores, pelo aumento da produção em diversos setores produtivos. $\mathrm{O}$ fator terra é o que apresenta maior valorização nos cenários 2 a 7 , devido à expansão do setor agropecuário e da agroindústria, consumidora dos produtos da agropecuária. Como as rendas dos consumidores são obtidas por meio da venda dos fatores de produção, a valorização dos fatores promove o aumento da renda e o conseqüente aumento do bem-estar.

Os cenários de formação do acordo entre MERCOSUL e UE (cenário 6) e de abertura comercial multilateral (cenário 3) são os que apresentam maiores valorizações nas remunerações dos fatores. Justamente estes cenários são os que trazem maiores impactos positivos de bem-estar para o Brasil.

Comparando os resultados dos cenários sob pressuposições alternativas no que diz respeito aos retornos de escala e natureza da competição, percebe-se que para todos os cenários os fatores de produção apresentam uma maior valorização no modelo com economias de escala e competição imperfeita, comparativamente ao modelo de retornos constantes e competição perfeita. Este resultado significa que está ocorrendo uma maior demanda pelos fatores de produção quando economias de escala são consideradas, devido ao aumento da produção pelo aproveitamento destas economias, o que pressiona por maiores aumentos na remuneração destes fatores e, por conseguinte, maiores aumentos na renda e no bem-estar dos consumidores. 


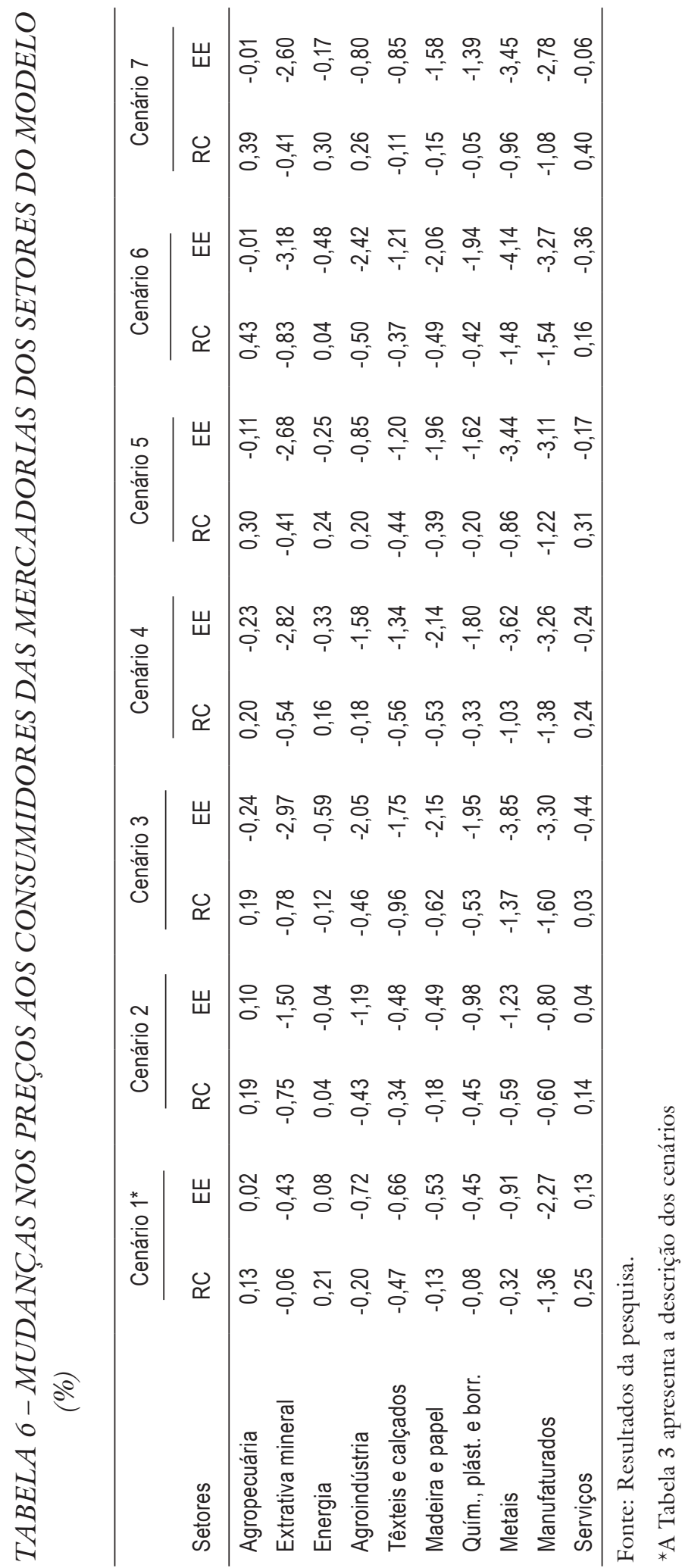




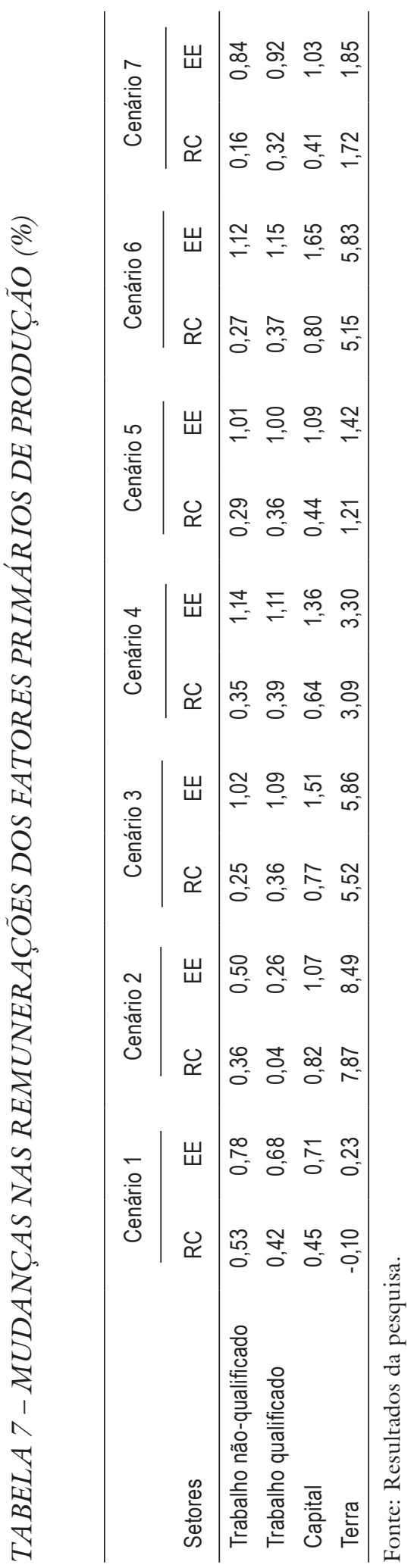


A partir dos resultados apresentados, pode-se notar que sob economias de escala e competição imperfeita as reduções nas barreiras comerciais, seja na forma de abertura comercial multilateral, seja na forma de acordos regionais, permitem o aumento da produção com aproveitamento de economias de escala e redução de markup nas indústrias com esses fenômenos, bem como redução de preços aos consumidores e aumento nas remunerações dos fatores primários de produção. Esses efeitos combinados permitem o aumento do bem-estar nos países beneficiados com a liberalização comercial. Os ganhos de bem-estar nos modelos tradicionais de retornos constantes e competição imperfeita são inferiores aos obtidos nos modelos com economias de escala, uma vez que os modelos tradicionais não incorporam os ganhos advindos do aproveitamento de economias de escala e redução de markup. Desta forma, os modelos de equilíbrio geral tradicionais geram menores aumentos na produção, efeitos menos pronunciados de reduções de preços e aumentos mais modestos nas remunerações dos fatores.

\section{CONCLUSÕES}

O estudo de comércio internacional é um dos campos que têm apresentado importantes avanços no que diz respeito ao tratamento dos fenômenos de economias de escala e competição imperfeita. Economias de escala podem influenciar os resultados de políticas comerciais em modelos de equilíbrio geral e, portanto, devem ser consideradas em estudos de políticas afetando o bem-estar dos países. Cenários ilustrativos de diminuição de barreiras comerciais foram simulados no estudo, contemplando a eliminação de impostos às exportações, formação de acordos regionais e liberalização multilateral. Os impactos dos cenários sobre o bem-estar são bem diferentes quando economias de escala e competição imperfeita são consideradas nas indústrias dos países, em comparação com os resultados obtidos em modelos sob competição perfeita e retornos constantes. Em muitos cenários, os ganhos de bem-estar no Brasil são três a quatro vezes superiores quando economias de escala são consideradas nos setores industriais.

Os cenários simulados permitem a racionalização dos setores industriais no Brasil, pela diminuição do número de firmas por indústria, com aumento da produção por firma, aproveitamento de economias de escala não exploradas e redução de markups. A agroindústria sofre o efeito pró-competitivo, uma vez que a diminuição das barreiras comerciais permite a expansão dos mercados, estimulando a entrada de novas firmas, aumento da produção por firma, aproveitamento de economias de escala e redução do markup.

Os resultados mais expressivos de bem-estar sob economias de escala e competição imperfeita estão relacionados com o aproveitamento destas economias e redução de 
markup nos setores industriais. Ocorrem, ademais, reduções de preços aos consumidores e aumentos nas remunerações dos fatores primários de produção mais expressivos no modelo com economias de escala, em comparação com o modelo com retornos constantes. Esses efeitos combinados permitem aumentos do bem-estar nos países beneficiados com a liberalização comercial, que são mais pronunciados quando os setores industriais são modelados com economias de escala e competição imperfeita. Desta forma, os modelos de equilíbrio geral tradicionais geram menores impactos no bem-estar advindos de políticas comerciais, já que ocorrem menores aumentos na produção, efeitos menos pronunciados de reduções de preços e aumentos mais modestos nas remunerações dos fatores.

Em suma, pode-se concluir que economias de escala e competição imperfeita são importantes na mensuração quantitativa de impactos de políticas comerciais, e devem, portanto, ser consideradas como elemento importante nas discussões dos acordos em pauta.

\section{ANEXO - ANÁLISE DE SENSIBILIDADE}

O parâmetro de escala $(s)$ define o grau de economias de escala inexploradas nos setores. Três situações diferentes foram consideradas para a análise de sensibilidade desse parâmetro: Situação 1: Brasil com $s$ igual aos dos países desenvolvidos no modelo original; Situação 2: Brasil com $s$ menor do que dos países desenvolvidos no modelo original; Situação 3: Países desenvolvidos com $s$ igual aos do Brasil no modelo original. A Tabela Al apresenta os resultados de bem-estar para o Brasil a partir das diferentes situações descritas para os parâmetros de escala, bem como os resultados de bem-estar obtidos no modelo original com economias de escala e competição imperfeita, apresentados no corpo do trabalho.

\section{TABELA AI - ANÁLISE DE SENSIBILIDADE SOBRE OS IMPACTOS EM BEM- ESTAR (\%) PARA O BRASIL SOB DIFERENTES VALORES PARA OS PARÂMETROS DE ESCALA}

\begin{tabular}{lccccccc}
\hline & Cenário 1 & Cenário 2 & Cenário 3 & Cenário 4 & Cenário 5 & Cenário 6 & Cenário 7 \\
\hline Modelo original & 0,35 & 0,36 & 1,23 & 1,00 & 0,78 & 1,20 & 0,63 \\
Situação 1 & 0,26 & 0,25 & 1,06 & 0,83 & 0,63 & 1,01 & 0,52 \\
Situação 2 & 0,19 & 0,17 & 0,94 & 0,70 & 0,53 & 0,86 & 0,41 \\
Situação 3 & 0,36 & 0,37 & 1,25 & 1,02 & 0,80 & 1,22 & 0,66 \\
\hline
\end{tabular}

Fonte: Resultados da pesquisa. 
A análise de sensibilidade do parâmetro de escala revela que os ganhos de bem-estar para o Brasil reduzem à medida que o grau de economias de escala inexploradas diminui. Os ganhos de bem-estar para o Brasil são praticamente iguais quando os países desenvolvidos são considerados com o mesmo grau de economias não exploradas que o Brasil (situação 3), em comparação com o modelo original, mostrando que variações no grau de economias de escala inexploradas de outros países alteram pouco os resultados de bem-estar para o Brasil.

Em relação às elasticidades Armington, duas situações foram consideradas para a alteração das elasticidades de transformação entre bens domésticos e exportáveis $(\eta)$, de substituição entre bens domésticos e importados $\left(\sigma_{\mathrm{dm}}\right)$ e entre bens importados de diferentes países $\left(\sigma_{\mathrm{mm}}\right)$. A Tabela A2 apresenta os valores dos parâmetros para essas situaçóes diante dos valores do modelo original (primeira linha da tabela) e mostra os resultados dessa análise sobre os impactos de bem-estar para o Brasil, para o modelo com economias de escala e competição imperfeita.

Os valores testados significam que estaria sendo aumentado o poder de mercado dos países no comércio mundial, à medida que a possibilidade de substituição se torna menor, e o grau de rigidez na conversão da produção para mercados diferentes estaria sendo aumentado.

\section{TABELA A2 - ANÁLISE DE SENSIBILIDADE SOBRE OS IMPACTOS EM BEM- ESTAR (\%) PARA O BRASIL SOB DIFERENTES VALORES PARA OS PARÂMETROS DE ELASTICIDADES ARMINGTON, SOB ECONOMIAS DE ESCALA}

\begin{tabular}{lccccccc}
\hline & Cenário 1 & Cenário 2 & Cenário 3 & Cenário 4 & Cenário 5 & Cenário 6 & Cenário 7 \\
\hline$\eta=8, \sigma_{\mathrm{dm}}=4, \sigma_{\mathrm{mm}}=8$ & 0,35 & 0,36 & 1,23 & 1,00 & 0,78 & 1,20 & 0,63 \\
$\eta=4, \sigma_{\mathrm{dm}}=2, \sigma_{\mathrm{mm}}=4$ & 0,13 & 0,04 & 0,64 & 0,52 & 0,41 & 0,56 & 0,26 \\
$\eta=2, \sigma_{\mathrm{dm}}=1, \sigma_{\mathrm{mm}}=2$ & 0,02 & $-0,19$ & 0,28 & 0,24 & 0,15 & 0,23 & $-0,01$ \\
\hline
\end{tabular}

Fonte: Resultados da pesquisa.

Os ganhos de bem-estar diminuem à medida que o poder de mercado dos países no comércio aumenta, e à medida que aumenta a rigidez na conversão de produtos domésticos em exportáveis. Em outras palavras, a liberalização comercial traria menores ganhos se não fosse permitido aos compradores mundiais mudarem de fornecedores menos eficientes para outros mais eficientes, e se produtores domésticos não pudessem aproveitar a oportunidade de fornecer para os mercados mundiais. Dessa forma, aumentos na produção com ganhos de escala, reduções de preços aos consumidores e aumentos nas remunerações dos fatores são menos intensos à medida que as elasticidades Armington diminuem, ou seja, à medida que as possibilidades de substituição diminuem. 


\section{REFERENCLAS}

Arrow, K. J.; Ng, Y. K.; Yang, X. Increasing returns and economic analysis. Macmillan Press, 1998. 457 p.

Athukorala, P., Reidel, J. Demand and supply factors in the determination of NIE exports: a simultaneous error-correction model for Hong Kong: a comment. Economic Journal, n. 104, p. 1411-1414, november 1994.

Barros, R. P. de.; Corseuil, C. H.; Cury, S. Abertura comercial e liberalização do fluxo de capitais no Brasil: impactos sobre a pobreza e a desigualdade. In: Henriques, R. (org.), Desigualdade e pobreza no Brasil. Rio de Janeiro: IPEA, 2000. p. 271-298.

Brooke, A.; Kendrick, D.; Meeraus, A.; Raman, R. GAMS: a user's guide. GAMS Development Corporation, 1998. 262 p.

Carvalho, A.; Parente A. Impactos comerciais da Área de Livre Comércio das Américas. Texto para Discussão, n. 635. Brasília: IPEA, 1999. 40p.

Cavalcante, J., Mercenier, J. Uma avaliação dos ganhos dinâmicos do Mercosul usando equilíbrio geral. Pesquisa e Planejamento Econômico, Rio de Janeiro, v. 29, n. 2, p. 153-184, 1999.

Devarajan, S.; Rodrik, D. Pro-competitive effects of trade reform: results from a CGE model of Cameroon. European Economic Review. v. 35, n. 5, p. 1157-1184, 1991.

Flôres, R. G. The gains from MERCOSUL: a general equilibrium, imperfect competition evaluation. Journal of Policy Modeling, v. 19, p. 1-18, 1997.

Global Trade Analysis Project - GTAP. Disponível em: (http://www.agecon. purdue. edu/gtap/), 2001.

Gurgel, A. C. Impactos econômicos e distributivos de mudanças nas relações comerciais da economia brasileira na presença de economias de escala. 2002. 198 p. Tese (Doutorado em Economia Aplicada), Universidade Federal de Viçosa, Viçosa, MG.

Gurgel, A. C.; Bitencourt, M. B.; Teixeira, E. C. Impactos dos acordos de liberalização comercial ALCA e MERCOEURO sobre os países membros. Revista Brasileira de Economia, v. 56, n. 2, p. 335-369, 2002.

Gurgel, A. C.; Campos, A. C. Impactos da ALCA sobre o agronegócio brasileiro na presença de economias de escala e competição imperfeita. Pesquisa e Planejamento Econômico, v. 33, n. 3, p. 435-480, 2003.

Harris, R. Applied general equilibrium model of small open economies with scale economies and imperfect competition. American Economic Review, v. 74, n. 5, p. 1016-1032, 1984.

Harrison, G. W.; Rutherford, T. F; Tarr, D. G. Chile's regional arrangements and the free trade agreement of the Americas. Washington D.C.: World Bank, 2001. 39p. (Policy Research Working Paper, 2634). 
Harrison, G. W.; Rutherford, T. F; Tarr, D. G.; Gurgel, A. Políticas de comércio regionais, multilaterais e unilaterais do Mercosul para o crescimento econômico e redução da pobreza no Brasil. Pesquisa e Planejamento Econômico, v. 33, p. 160, 2003.

Hoffman, A. N. Imperfect competition and economic policy. Copenhagen: University of Copenhagen, Ph.D. thesis (Copenhagen Business School), p. 23-57, 2001.

Krugman, P. R. Increasing returns, monopolistic competition, and international trade. Journal of International Economics, v. 9, p. 469-479, 1979.

Lancaster, K. Variety, equity, and efficiency. New York: Columbia University Press, 1979.

Markusen, J. R.; Rutherford, T. F; Hunter, L. Trade liberalization in a multinationaldominated industry. Journal of International Economics, v. 38, n. 1-2, p. 95-117, 1995.

Pratten, C. F. Economies of scale in manufacturing industry. Cambridge University Press, 1971. 352 p. (Occasional paper 28).

Reidel, J. The demand for LDC exports of manufactures: estimates from Hong Kong. Economic Journal, n. 98, p. 138-148, march 1988.

Roland-Holst, D. W.; Reinert, K. A.; Shiells, C. R. A general equilibrium analysis of North American integration. In: Francois, F. J.; Shiells, C. R. (eds.), Modeling trade policy: applied general equilibrium assessments of North American free trade. Cambridge University Press, 1994, p. 47-82.

Rutherford, T. F. Extensions of GAMS for complementarity problems arising in applied economics. Journal of Economic Dynamics and Control, v. 19, n. 8, p. 1299-1324, 1995.

Applied general equilibrium modeling with MPSGE as a GAMS subsystem: an overview of the modeling framework and syntax. Computational Economics, v. 14, n. 1, p. 1-46, 1999.

Rutherford, T. F.; Paltsev, S. V. GTAPinGAMS and GTAP-EG: global datasets for economic research and illustrative models. Boulder: Department of Economics - University of Colorado, 2000. 64 p. (Working Paper).

Sadoulet, E.; De Janvry, A. Quantitative development policy analysis. Baltimore: The John Hopkins University, 1995. 397 p.

Tourinho, O.; Kume, H. Os impactos setoriais de acordos de comércio: análise com um modelo CGE da economia brasileira. Rio de Janeiro: IPEA, 2002. Mimeografado.

Valls Pereira, L. Impactos do Mercosul, da Alca e do acordo MS-UE na economia brasileira e argentina: um mapeamento preliminar. Ibre, 2001. Mimeografado.

Walmsley, T.; McDougall, R. Overview of regional input-output tables. Disponível em: (http://www.gtap.agecon.purdue.edu/databases/v5/v5_doco.asp), 2001. 